\title{
SIMULATION OF RELIABILITY PREDICTION BASED ON MULTIPLE FACTORS FOR SPINNING MACHINE
}

\author{
Chen Li, Rongxing Liu, Fukui Pan \\ Textile Science Research Institute, Qingdao University, Qingdao, China 266071 \\ E-mail: Icqdute@126.com
}

\begin{abstract}
:
Reliability prediction of spinning machines can result in a time-saving and cost-saving development process with high reliability. Based on an analysis of failure times among systems and subsystems, a simulation method for reliability prediction of spinning machines is proposed by using the Monte Carlo simulation model. Firstly, factor weights are determined according to the fuzzy scoring and analytic hierarchy process. According to the status of reliability growth, growth coefficients are proposed based on reliability influencing factor weights and fuzzy scoring. To achieve the prediction of reliability distribution law, reliability index, and fault frequency, the reliability prediction model is constituted by combining the reliability growth coefficient and the Monte Carlo simulation model. Simulation results for spinning machines are obtained via the model thus built, which are confirmed with a practical example.
\end{abstract}

\section{Keywords:}

spinning machines, reliability prediction, Monte -Carlo simulation, reliability growth

\section{Introduction}

During the process of research and development (R\&D) of a spinning machine, reliability prediction [1-4] is an important cycle of reliability design. A product could be designed or improved through reliably predicting and correctly assessing in order to adopt appropriate measures if necessary; this will be good for saving the R\&D cost and shortening the R\&D cycle; in addition, it has a significant effect on improving reliability.

Spinning machine belongs to a complicated system of mechanical-electrical integration [5], but the methods used to predict the reliability, including similar equipment method [6], mathematic analysis method (such as the series-parallel connection model method, and the Markov process method $[7,8])$ have not been ripe. The similar equipment method depends on the degree of similarity of equipment; the seriesparallel model method is too idealistic, for it requires knowledge of all reliable data of each unit in the system; and the Markov process method requires every unit to obey exponential distribution. The methods mentioned above do not apply to reliability prediction of a machine, as there are two difficulties: first, it is hard to build a quantitative prediction model. Second, due to the lack of required information and data, there is a lack of relevant data reliability. Only by solving these two technical difficulties and by improving the science of predicting can we ensure that the predictive result is more accurate. This article presents the comprehensive prediction methods based on Monte Carlo simulation $[3,4]$ and solves the difficulty related to the lack of sample data for reliability prediction.

As far as I am concerned, there has been less research on the reliability of spinning machines, and the research on reliability prediction has been even less. This article presents the comprehensive prediction methods based on Monte Carlo simulation $[3,4]$ and solves the difficulty related to the lack of sample data for reliability prediction. Taking a machine as example, considering various factors that affect the machine, we adopt methods of fuzzy evaluation $[9,10]$ and analytic hierarchy $[10,11]$ to confirm the weights of various factors and, thereafter, put forward the concept of growth factor of reliability, build up a quantitative model for the factors affecting reliability, and combine the quantitative model with Monte Carlo simulation to predict the reliability; this method is based on the Weibull distribution model $[12,13]$, which is a comprehensive method aiming to improve a machine to predict the growth of reliability.

\section{Reliability prediction model}

\section{Reliability projection process}

The reliability prediction process is undertaken as shown in Figure 1. First, we build a reliability model of the original whole machine based on fault data from history and field experiments. We obtain the reliability simulation model of a subsystem of the original whole machine through Monte Carlo simulation according to the reliability model of the original machine and historical failure frequency of the subsystems. We then determine the reliability growth factor of a subsystem of a new machine through the weight of the reliability influencing factor based on analytic hierarchy process and expert fuzzy scoring of the reliability growth of the improved machine's subsystems. Subsequently, on the basis of the reliability simulation model of the subsystem of the original machine and the reliability growth factor of the subsystem of the new machine, we build the reliability model of the subsystem of the new machine. Finally, we establish the reliability model of the new machine according to the simulating relation between the subsystem of the new machine and the whole machine, as well as achieving the reliability prediction of the new machine after improvement. 


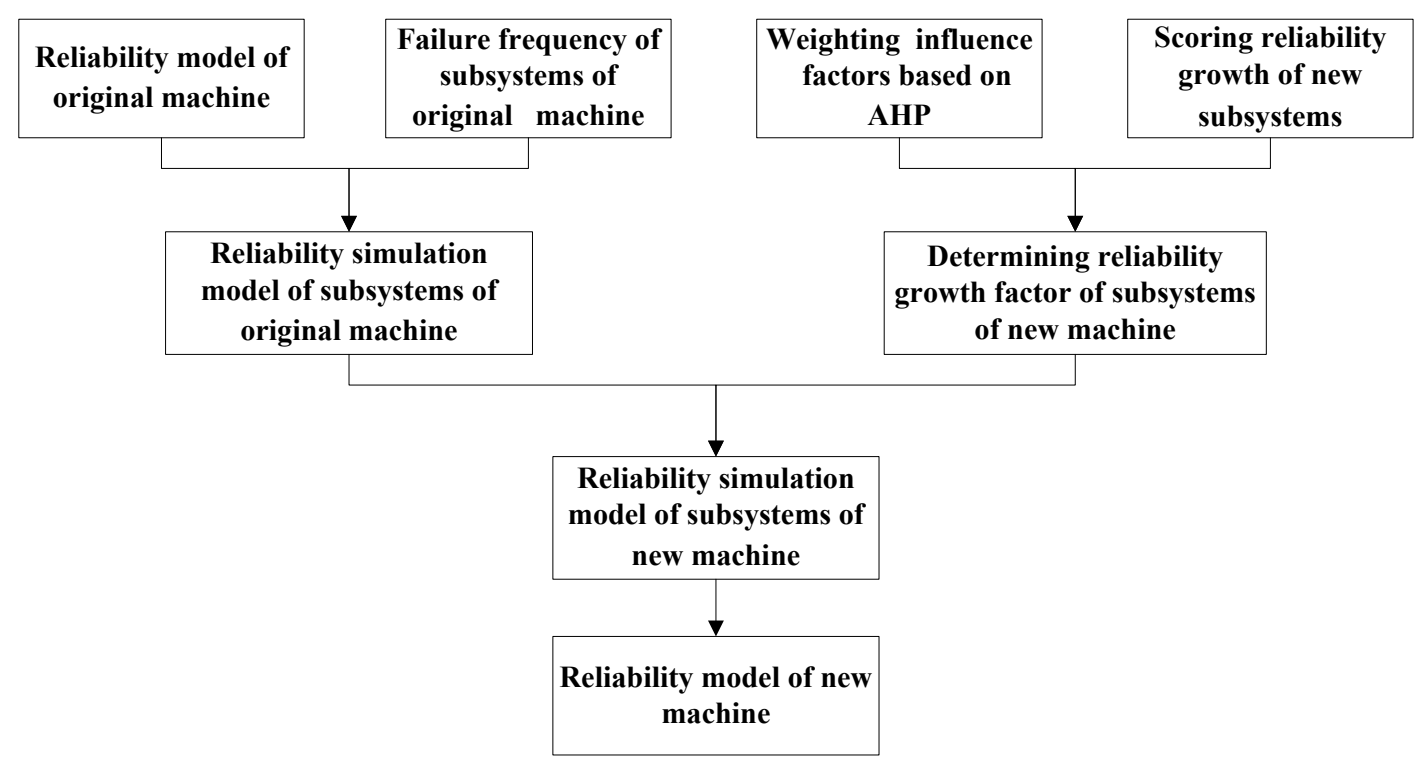

Figure 1. Technological process of reliability prediction.

Mean time between failures (MTBF) mapping relation model of whole machine and subsystems

Take $\mathrm{T}_{\mathrm{k}}$ as full life circle of a spinning machine, $\boldsymbol{N}$ as total failures of this machine, $\mathrm{n}$ as the number of subsystem; $\mathrm{N}_{\mathrm{k}}$ represents the total failures of the $\mathrm{k}_{\mathrm{th}}$ subsystem, $\mathrm{p}_{\mathrm{k}}$ represents the failure frequency of the $k_{\text {th }}$ subsystem, $m_{k}$ represents the mean time between failures (MTBF) index value of the subsystem, and $m_{k}$ represents the MTBF index value of the whole machine; obviously, there exists the following theoretical Equation (1):

$$
\left\{\begin{array}{c}
m_{s}=\frac{T_{s}}{N} \\
m_{k}=\frac{T_{s}}{N_{k}} \\
N_{k}=N p_{k} \\
\sum_{k=1}^{n} p_{k}=1
\end{array}\right.
$$

We obtain the MTBF mapping relation model of the whole machine and the subsystems as shown in Equation (2):

$$
\frac{1}{m_{s}}=\sum_{k=1}^{n} \frac{1}{m_{k}}
$$

Weight model of reliability influencing factors

Reliability evaluation index has high sensitivity to the weights of the influencing factors; therefore, it is very important to determine the weights of the influencing factors. In this paper, we adopt the analytic hierarchy process to determine weight.

At first, we construct and judge the matrix as shown in Equation (3):

$$
D=\left[\begin{array}{cccc}
u_{11} & u_{12} & \cdots & u_{1 n} \\
u_{21} & u_{22} & \cdots & u_{2 n} \\
\vdots & \vdots & \vdots & \vdots \\
u_{n 1} & u_{n 2} & \cdots & u_{n n}
\end{array}\right]
$$

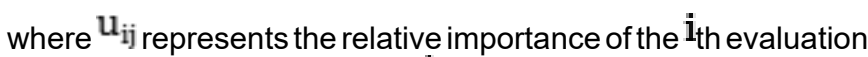
factor with reference to the $j_{\text {th }}$ evaluation factor. Here, $u_{i j}$ represents the relative importance of the $j_{\text {th }}$ evaluation factor with reference to the $i_{\text {th }}$ evaluation factor, and its value is the reciprocal of $\mathrm{u}_{\mathrm{ij}}$.

Calculating and judging the maximum characteristic root $\lambda_{\max }$ and substituting into the set of homogeneous linear equations [Equation (4)]:

$$
\left\{\begin{array}{c}
\left(u_{11}-\lambda\right) w_{1}+u_{12} w_{2}+\cdots+u_{1 n} w_{n}=0 \\
u_{21} w_{1}+\left(u_{22}-\lambda\right) w_{2}+\cdots+u_{2 n} w_{n}=0 \\
\cdots \\
u_{n 1} w_{1}+u_{n 2} w_{2}+\cdots+\left(u_{n n}-\lambda\right) w_{n}=0
\end{array}\right.
$$

Solving $\mathrm{w}_{1}, \mathrm{w}_{2}, \cdots, \mathrm{w}_{\mathrm{n}}$, we obtain the eigenvector (5) corresponding to the maximum characteristic root $\lambda_{\max }$,

$$
W=\left(w_{1}, w_{2}, \cdots, w_{n}\right)
$$

We normalize $\boldsymbol{W}$ to obtain the quantitative weight of the influencing factors and quantify the importance of the various influencing factors. Finally, we conduct the consistency inspection according to Equation (6):

$$
C R=\frac{C I}{R I}
$$

where $\mathrm{CR}$ is the random consistency ratio of the judgment matrix; $\mathrm{CI}$ is the common consistency indicator of the judgment matrix, and its value is $C I=\left(\lambda_{\max }-n\right) /(n-1) ; \mathrm{RI}$ is the average random consistency indicator of the judgment matrix, and the judgment matrix is of the fifth to ninth order. The value of $\mathrm{RI}$ is shown in Table 1. 
Table 1. The RI value for the consistency test of comparison matrix

\begin{tabular}{|c|c|c|c|c|c|}
\hline $\mathbf{n}$ & $\mathbf{5}$ & $\mathbf{6}$ & $\mathbf{7}$ & $\mathbf{8}$ & $\mathbf{9}$ \\
\hline $\mathrm{RI}$ & 1.12 & 1.24 & 1.32 & 1.41 & 1.45 \\
\hline
\end{tabular}

When $C R<0.1$, the judgment matrix is regarded as having satisfied consistency, indicating reasonable weight allocation; otherwise, expert scoring should be carried out again until satisfactory consistency is obtained.

\section{Reliability growth coefficient model}

We use the linear weighting method to obtain the comprehensive score of each subsystem of each influencing factor of the subsystems of the original machine and the improved new machine, as well as the weight of the reliability influencing factor. The comprehensive scoring model of the subsystem is shown in Equation (7):

$$
G_{k}=\sum_{i=1}^{q} \omega_{i} g_{k i} \quad k=1, \cdots, n ; i=1, \cdots, q
$$

where $\mathrm{G}_{\mathrm{k}}$ is the comprehensive score of the $\mathrm{k}_{\mathrm{th}}$ subsystem; $\omega_{\mathrm{i}}$ is the weight of the $\mathrm{i}_{\text {th }}$ influencing factor; and $g_{k i}$ is the score of the $\mathrm{i}_{\text {th influencing factor. }}$

The reliability growth coefficient of the subsystems can be defined as the ratio $C_{k}$ between the score $G_{k}$ of the new machine and the score $G_{k}$ of the original machine, i.e., Equation (8):

$$
C_{k}=\frac{G_{k}^{\prime}}{G_{k}}=\frac{X_{k}^{\prime}}{X_{k}}
$$

\section{Simulation of reliability sample data}

We use Weibull distribution to carry out reliability modeling on the sample data of trouble-free working time of the machine. Then, we use Monte Carlo simulation to obtain the troublefree working time sample $\boldsymbol{X}_{\boldsymbol{k}}$ of the subsystems of the original machine according to the reliability distribution law of the original machine. Then, we obtain the trouble-free working time sample $\mathrm{X}_{\mathrm{k}}$ of the subsystems of the new improved machine according to the reliability growth coefficient model and convert into the trouble-free working time sample $\mathrm{X}$ of the new machine. We conduct reliability modeling on $\mathrm{X}$ to obtain the result of the simulated prediction of the new machine. The trouble-free working times are shown in Figure 2, wherein $\boldsymbol{T}_{i}$ indicates the working time corresponding to the $j_{\text {th }}$ failure of the $\mathrm{i}_{\text {th subsystem. }}$

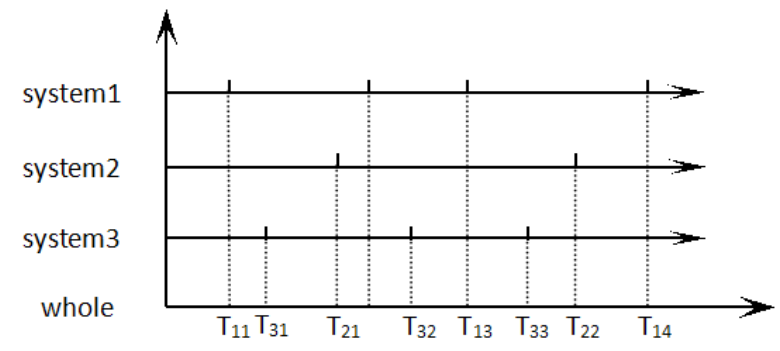

Figure 2. Relationship of the working time between failures for the whole machine and subsystems.
We then conduct reliability modeling on the sample data of trouble-free working time to obtain the Weibull distribution law. The simulation sample $\mathrm{X}=\left(\mathrm{x}_{1}, \cdots, \mathrm{x}_{\mathrm{k}}, \cdots, \mathrm{x}_{\mathrm{s}}\right)$ of trouble-free working time of the original machine is produced according to Weibull distribution, assorted according to sequence, and converted into sample $\mathrm{T}=\left(\mathrm{t}_{1}, \cdots, \mathrm{t}_{\mathrm{k}}, \cdots, \mathrm{t}_{\mathrm{s}}\right)$ of the original machine in failure, where $t_{i}$ is calculated according to Equation (9):

$$
\boldsymbol{t}_{i}=\sum_{j=1}^{i} \boldsymbol{x}_{j}
$$

We then randomly assigned each element $t_{i}$ in $T$ to the $k_{\text {th }}$ subsystem according to the probability of $\boldsymbol{p}_{\boldsymbol{k}}$ (failure frequency of the $\mathrm{k}_{\text {th }}$ subsystem) and obtained the simulation sample $\left\{\mathrm{T}_{1}, \cdots, \mathrm{T}_{\mathrm{k}}, \cdots, \mathrm{T}_{\mathrm{n}}\right\}$ of the subsystems of the original machine at the time of failure. The simulation sample $\left\{\mathrm{X}_{1}, \cdots, \mathrm{X}_{\mathrm{k},}, \cdots, \mathrm{X}_{\mathrm{n}}\right\}$ of the subsystems of the original machine at failure time is obtained according to the simulation sample of the subsystems of the original machine.

The simulation sample $\left\{\mathrm{X}_{1}^{\prime}, \cdots, \mathrm{X}_{\mathrm{k}}^{\prime}, \cdots, \mathrm{X}_{\mathrm{n}}^{\prime}\right\}$ of the new machine in trouble-free working time is obtained according to the simulation sample $\left\{\mathrm{X}_{1}, \cdots, \mathrm{X}_{\mathrm{k}}, \cdots, \mathrm{X}_{\mathrm{n}}\right\}$ of the trouble-free working times of the subsystems of the original machine and the reliability growth factor model, where $\quad \mathrm{x}_{\mathrm{k}}^{\prime}=\left(\mathrm{x}_{\mathrm{k} 1}^{\prime}, \cdots, \mathrm{x}_{\mathrm{kj}}^{\prime}, \cdots, \mathrm{x}_{\mathrm{km}}^{\prime}\right) \quad \mathrm{j}=(1,2, \cdots, \mathrm{m})$ the subscript $\mathrm{j}=(1,2, \cdots, \mathrm{m})$ in sample $\mathrm{X}_{\mathrm{k}}$ is the failure sequence of the subsystems, converted into the failure time $\mathrm{T}_{\mathrm{k}}^{\prime}=\left(\mathrm{t}_{\mathrm{k} 1}, \cdots, \mathrm{t}_{\mathrm{kj}}, \cdots, \mathrm{t}_{\mathrm{km}}\right)$. Here, $\mathrm{t}_{\mathrm{kj}}$ is calculated according to Equation (10): take $\mathrm{t}_{\min }=\operatorname{Min}\left(\mathrm{t}_{1 \mathrm{~m}}^{\prime}, \cdots, \mathrm{t}_{\mathrm{km}}^{\prime}, \cdots, \mathrm{t}_{\mathrm{nm}}^{\prime}\right)$ as the termination time of the failure observation of the whole machine.

$$
\boldsymbol{t}_{k j}^{\prime}=\sum_{i=1}^{j} \boldsymbol{x}_{k i}^{\prime}
$$

The total failure time of the whole machine is $\mathrm{T}^{\prime}$. All the failure times (equal to or less than $t_{\text {min }}$ ) are arranged to obtain failure time sequence of the whole machine in the time zone $\left[0, t_{\min }^{\prime}\right]$, and thereafter are converted to get the simulation sample $\mathrm{X}^{\prime}=\left(\mathrm{x}_{1}, \cdots, \mathrm{x}_{\mathrm{k}}, \cdots, \mathrm{x}_{\mathrm{s}}\right)$ of the no-failure working time of the whole machine. Thus, reliability modeling and reliability prediction can be carried out for the improved machine.

\section{Reliability prediction case}

\section{Description of case}

In this case, a spinning machine is selected as the reliability prediction object. Statistics on the failure frequencies of the subsystems of the original machine is obtained based on the maintenance record of the original machine. Subsequently, a 3-month field track test was conducted on the original machine and the reliability model of the original machine was established according to the operation records and failure records. Determination of the main factors affecting the reliability of the machine was done through communication with the designers of the machine. Fuzzy scoring was done by the designer through comparison of the machine before and after improvement. The reliability prediction model is 
then used to predict the reliability distribution law of the new machine.

\section{Data collection and processing}

The collection of reliability data of the machine was done by the field track mode, recording the operation state, failure time, failure cause, and so on in real time. Further, data screening was done according to relevant specifications on reliability data screening regulations, ensuring authentic fault data.

Through field data collection method, the fault data of 10 spinning machines of certain user enterprises was collected for 3 months; the period was from May 11, 2017 to August 11, 2017. The relevant reliability data examined are shown in Table 2.

The spinning machine was divided into several subsystems and then the frequency list of the subsystems was obtained as shown in Table 3.

There are many factors influencing the reliability of a spinning machine, mainly including functional complexity, structural complexity, repairability (level of recovery), technical level (materials, processing, assembly, and so on), quality of components (stability of components), workload (level and frequency), environmental conditions (air temperature, humidity, and cleanliness), maintenance state, and so on.

We determined the list of reliability influencing factors based on the influence analysis of the machine's failure mode and by communication with designer, as shown in Table 4 . We then worked out the comparison scoring table of the reliability influencing factors of the spinning machine by adopting the analytic hierarchy process to determine the weights of the influencing factors, in order to facilitate the scoring by the designers.

According to the scores arrived at by the designers based on Table 4, we obtained the average comparison score of the reliability influencing factor of the machine, as shown in Table 5.

\section{Determination of reliability growth factor}

According to the score determined by the designers based on Table 2, we obtained the average score of the reliability influencing factor of the subsystems of a spinning machine, as shown in Table 7.

We solved the reliability growth coefficient of the subsystems of the new machine relative to the original machine according to the reliability growth coefficient model and the score table of the influencing factors of the subsystems of the machine, as shown in Table 9.

\section{Prediction result and analysis}

We obtained the reliability parameter of the original machine and the new machine according to the reliability prediction model and the case data. In order to verify the accuracy of the prediction method, we also used the field track mode to obtain the fault data of the new machine and calculated the reliability indicator.

We then listed the relative errors of the actually estimated values of the new spinning machine and the predicted Weibull distribution parameters by using the model to simulate 1000 times, as shown in Table 10.

Table 2. Reliability data for the MTBF index of a spinning machine

\begin{tabular}{|c|c|c|c|c|c|c|c|c|c|c|}
\hline Numbers & 1 & 2 & 3 & 4 & 5 & 6 & 7 & 8 & 9 & 10 \\
\hline \multirow{4}{*}{ Time between failures, hours } & 47 & 229 & 1144 & 133 & 265 & 117 & 597 & 387 & 134 & 904 \\
\hline & 200 & 1192 & 335 & 194 & 776 & 133 & 108 & 100 & 145 & 506 \\
\hline & 270 & 327 & 266 & 142 & 275 & 133 & - & 465 & 1073 & 94 \\
\hline & - & 516 & - & 397 & - & 399 & 328 & - & 532 & - \\
\hline
\end{tabular}

Table 3. Failure frequencies of the old machine

\begin{tabular}{|l|c|}
\hline Subsystems & Frequency, \% \\
\hline Drive system & 8.58 \\
\hline Electrical system & 13.67 \\
\hline Drafting system & 22.50 \\
\hline Winding system & 18.75 \\
\hline Twist system & 14.50 \\
\hline Tooling system & 22.00 \\
\hline
\end{tabular}

Table 4. Factors influencing reliability of a spinning machine

\begin{tabular}{|c|c|c|c|c|c|c|c|}
\hline Number & $\mathbf{1}$ & $\mathbf{2}$ & $\mathbf{3}$ & $\mathbf{4}$ & $\mathbf{5}$ & $\mathbf{6}$ & $\mathbf{7}$ \\
\hline Influencing factor & Function & Structure & Repairability & $\begin{array}{c}\text { Technical } \\
\text { level }\end{array}$ & $\begin{array}{c}\text { Component } \\
\text { quality }\end{array}$ & Maintenance & Workload \\
\hline
\end{tabular}


Table 5. Scoring data for comparison of the reliability influencing factors

\begin{tabular}{|c|c|c|c|c|c|c|c|c|c|c|c|c|c|c|}
\hline \multirow{2}{*}{$\begin{array}{c}\text { Influencing factors } \\
1\end{array}$} & \multicolumn{2}{|c|}{1} & \multicolumn{2}{|c|}{2} & \multicolumn{2}{|c|}{3} & \multicolumn{2}{|c|}{4} & \multicolumn{2}{|c|}{5} & \multicolumn{2}{|c|}{6} & \multicolumn{2}{|c|}{7} \\
\hline & - & - & - & - & - & - & - & - & - & - & - & - & - & - \\
\hline 2 & 1 & 5 & - & - & - & - & - & - & - & - & - & - & - & - \\
\hline 3 & 1 & 5 & 1 & 4 & - & - & - & - & - & - & - & - & - & - \\
\hline 4 & 5 & 1 & 3 & 1 & 7 & 1 & - & - & - & - & - & - & - & - \\
\hline 5 & 4 & 1 & 4 & 1 & 5 & 1 & 1 & 3 & - & - & - & - & - & - \\
\hline 6 & 1 & 1 & 4 & 1 & 3 & 1 & 1 & 4 & 1 & 1 & - & - & - & - \\
\hline 7 & 2 & 1 & 1 & 1 & 5 & 1 & 1 & 3 & 1 & 2 & 1 & 1 & - & - \\
\hline
\end{tabular}

Note: We filled out the score of the horizontal index relative to the vertical index on the left side of a blank form and filled out the score of the vertical index relative to the horizontal index on the right side (refer to Table 6). The score must be an integer between zero and nine.

Table 6. Scoring scale for comparison of reliability influencing factors

\begin{tabular}{|c|c|}
\hline Levels & Implication \\
\hline 1 & Equally important \\
\hline 3 & Commonly important \\
\hline 5 & Fairly important \\
\hline 7 & Greatly important \\
\hline 9 & Extremely important \\
\hline $2,4,6,8$ & Between the above respective levels \\
\hline
\end{tabular}

Table 7. Mean scoring for the reliability influencing factors of spinning machine subsystems

\begin{tabular}{|c|c|c|c|c|c|c|c|c|c|c|c|c|c|c|}
\hline \multirow[b]{2}{*}{ Drive system } & \multicolumn{2}{|c|}{1} & \multicolumn{2}{|c|}{2} & \multicolumn{2}{|c|}{3} & \multicolumn{2}{|c|}{4} & \multicolumn{2}{|c|}{5} & \multicolumn{2}{|c|}{6} & \multicolumn{2}{|c|}{7} \\
\hline & 5 & 5 & 4 & 6 & 5 & 5.5 & 6 & 7 & 5 & 6 & 5 & 6.5 & 7 & 7 \\
\hline Electrical system & 4 & 6 & 4 & 7 & 5 & 6 & 4 & 8 & 6 & 7 & 3 & 8 & 5 & 7.5 \\
\hline Drafting system & 5 & 7 & 4 & 7.5 & 6 & 8 & 6 & 7.5 & 5 & 9 & 6 & 7.5 & 4 & 8 \\
\hline Winding system & 3 & 7 & 5 & 7 & 4 & 5 & 5 & 8.5 & 4 & 7 & 4 & 6 & 5 & 8 \\
\hline Twist system & 4 & 8 & 6 & 8 & 4 & 7 & 6.5 & 8 & 5 & 9 & 4 & 8 & 7 & 5 \\
\hline Tooling system & 5 & 6 & 3 & 7.5 & 5 & 7 & 4 & 6 & 5 & 6 & 5.5 & 7.5 & 6 & 7.5 \\
\hline
\end{tabular}

Note: Score on the left is for the original machine, and the score on the right is for the new machine. For scoring, please refer to Table 8.

Table 8. Scoring scale for the reliability influencing factors

\begin{tabular}{|c|c|c|c|c|}
\hline Levels & \multicolumn{3}{|c|}{ Implication } \\
\hline $0-2$ & Very easy & Very poor & Very low & Very little \\
\hline $2-4$ & Easy & Poor & Low & Little \\
\hline $4-6$ & Average level & Average level & Average level & Average level \\
\hline $6-8$ & Complicated & Good & High & Big \\
\hline $8-10$ & Very complicated & Very good & Very high & Vig \\
\hline
\end{tabular}


Table 9. Growth coefficients of the spinning machine subsystems

\begin{tabular}{|c|c|c|c|c|c|c|}
\hline Subsystems & $\mathbf{1}$ & $\mathbf{2}$ & $\mathbf{3}$ & $\mathbf{4}$ & $\mathbf{5}$ & $\mathbf{6}$ \\
\hline Growth coefficient & 1.1614 & 1.6884 & 1.4696 & 1.6809 & 1.4145 & 1.3772 \\
\hline
\end{tabular}

Table 10. Comparison of reliability distribution parameters and errors

\begin{tabular}{|c|c|c|c|}
\hline Parameters & Scale parameter & Shape parameter & MTBF, hours \\
\hline Old machine & 414.94 & 1.3368 & 381.18 \\
\hline New machine & 560.72 & 1.1429 & 432.7 \\
\hline Prediction & 562.30 & 1.0365 & 554.22 \\
\hline
\end{tabular}
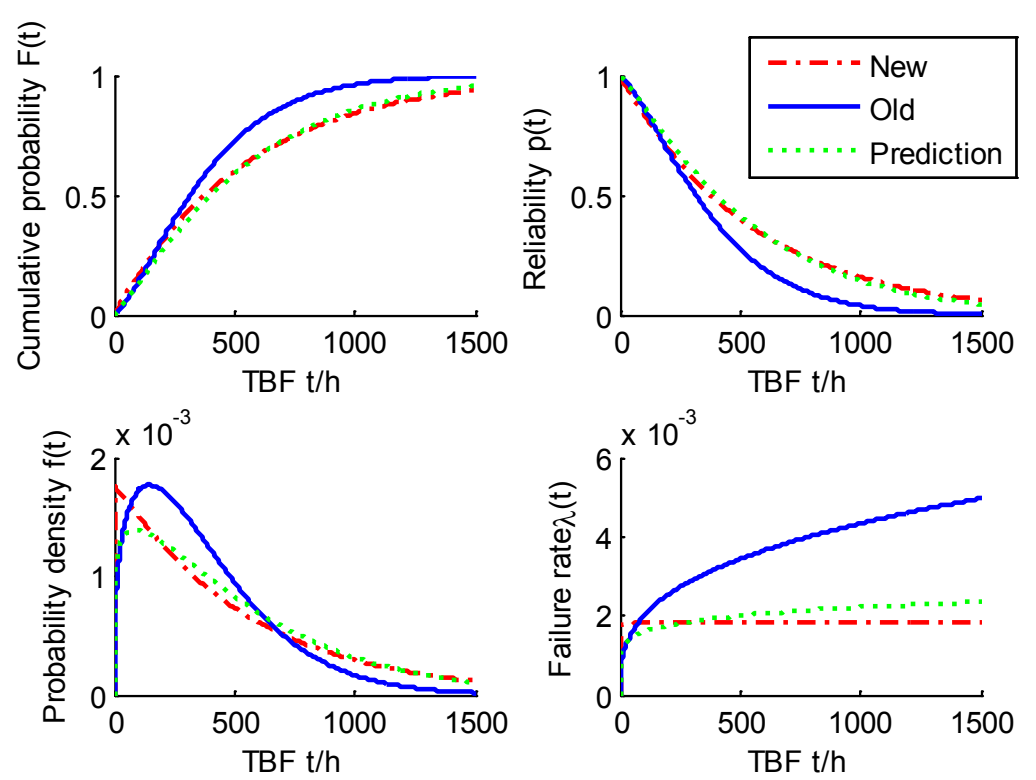

Figure 3. Comparison of the reliability distribution law of the spinning machine.

Table 11. Comparison of the failure frequency of the machine's subsystems

\begin{tabular}{|c|c|c|c|c|c|c|}
\hline Subsystems & Drive system & $\begin{array}{c}\text { Electrical } \\
\text { system }\end{array}$ & $\begin{array}{c}\text { Drafting } \\
\text { system }\end{array}$ & $\begin{array}{c}\text { Winding } \\
\text { system }\end{array}$ & Twist system & Tooling system \\
\hline Old machine, \% & 8.58 & 13.67 & 22.5 & 18.75 & 14.5 & 22 \\
\hline New machine, \% & 10.67 & 11.75 & 21.88 & 16 & 14.76 & 22.8 \\
\hline Prediction, \% & 12.73 & 14.81 & 23.94 & 16.55 & 10.88 & 21.09 \\
\hline
\end{tabular}

Table 10 shows a list of the actually estimated reliability parameters of the original and new machines, as well as the average reliability parameters of the new machine obtained by using the reliability prediction model to simulate 1000 times. It can be seen that the prediction error of the shape parameter is relevant and big according to the relative prediction error; this is because the new machine is not at the occasional failure period of the bathtub curve.

As shown in Figure 3, the actual distribution law and the prediction result of the new spinning machine are basically the same, because the shape parameter of the reliability distribution is larger. In addition, the reliability level of the new machine is obviously improved.
As shown in Table 11, the difference among the subsystem failure frequencies of the original machine, the new machine, and the prediction value is not big, indicating that the prediction result of failure frequency is good, the improved parts of the machine are relatively balanced, and the reliability of the subsystems has been enhanced.

\section{Conclusions}

This paper enumerates the main factors that affect the reliability of spinning machines. These factors are quantitatively described by expert fuzzy scoring and analytic hierarchy process. A simulation relation model of reliability is established by using the Monte Carlo simulation model. The simulation results 
obtained from the simulation model confirm the efficiency and practicability in MatLab. The feasibility of the prediction method is verified using an actual case, and the average relative error of the MTBF prediction value is controlled within $5 \%$, which indicates that the accuracy of the prediction method mentioned in the paper is relevantly high. This method presented in our paper provides a powerful theoretical basis and method for the reliability design of spinning machines during the design process.

\section{References}

[1] Shi, J., (2011). Reliability prediction methods and application of large capacity generating units. Journal of Mechanical Engineering, 47(18), 165-172. (in Chinese)

[2] Kuo, Y., Lin, K., (2010). Using neural network and decision tree for machine reliability prediction. International Journal of Advanced Manufacturing Technology, 50(9-12), 12431251.

[3] Asri, Y. M., Azrulhisham, E. A., Dzuraidah, A. W., A. Shahrir, A. Shahrum, et al., (2011). Fatigue life reliability prediction of a stub axle using Monte Carlo simulation. International Journal of Automotive Technology, 12(5), 713-719.

[4] Naess, A., Leira, B J, Batsevych O., (2009). System reliability analysis by enhanced Monte Carlo simulation. Structural Safety, 31(5), 349-355.

[5] Dey, S, Sarmah, P. (1995). Estimation of parameters of a model of a complex repairable system. Microelectronics
Reliability, 37(4), 673-676.

[6] Yang, M, Lin, Z, He B., et al. (2003). Reliability prediction of mechanical product based on similarity. Machine Tool \& Hydraulics, (1), 63-65. (in Chinese)

[7] Gaver, D. P. (1963). Time to failure and availability of paralleled system with repair. IEEE Transactions on Reliability, 12, 30-38.

[8] Cox, D. R. (1955). The analysis of non-Markovian stochastic processes by the inclusion of supplementary variables. Cambridge Phil, 51, 433-441.

[9] Yang, Z., Hao, Q, Chen F, et al. (2011). A comprehensive fuzzy reliability allocation method of NC machine tools based on interval analysis. Journal of Beijing University of Technology, 37(3), 321-329. (in Chinese)

[10] Wang, S., Li, S, Zhou, J., Li, Q., Kang, L., (2012). Reliability allocation for CNC machine based on improved fuzzy analytic hierarchy process. Advances in Information Sciences and Service Sciences, 4(1), 320-327.

[11] Peng, B., Zhao, J., Sun, Q., (2005). Reliability allocation method for complex system using AHP. Electronic Product Reliability and Environmental Testing, 23(6), 58-62. (in Chinese)

[12] Zhang, H., Jia, Y., Zhou, G., (2007). Time between failures model and failure analysis of CNC system. Journal of Harbin Institute of Technology, 14(2), 197-201.

[13] Shen, G., Chen, B., Zhang, Y., et al. (2011). Reliability model for subsystems of CNC machine tool with small samples. Journal of Chongqing University, 34(8), 55-59. 